\title{
Appetitive control of responding in the presence of free food: Effects of d-amphetamine and fenfluramine
}

\author{
ARNOLD B. DAVIDSON and DIXON J. DAVIS \\ Smith Kline and French Laboratories, Philadelphia, Pennsylvania 19101
}

\begin{abstract}
d-Amphetamine (1-4 mg/kg) significantly decreased responding for food in the presence of free food. This effect is opposite to that obtained in experiments on motor activity and responding for stimulus change but is in agreement with predictions based on its anorectic activity. Fenfluramine $(2-8 \mathrm{mg} / \mathrm{kg})$, an anorectic with qualitatively different effects on motor activity at anorectic doses, similarly decreased responding for food in the presence of free food. These results suggest that the appetitive properties of response contingent food play a major role in the maintenance of responding in the presence of free food, even if only as part of a stimulus complex whose significance was established during early training.
\end{abstract}

Although current interest in the phenomenon of animals responding for food in the presence of identical free food was first stimulated by findings in rats (Jensen, 1963), Carder and Berkowitz (1970) reported that responding for food could not be maintained at a ratio of more than two responses per reinforcement (FR 2). Singh (1970), working with better trained rats, and Neuringer (1970), working with well-trained pigeons, found that these animals would work at reasonably high ratios (FR 11 and FR 40, respectively) in the presence of free food. In a previous paper (Davidson, 1971), it was found that well-trained rats responded on an FR 10 in the presence of free food for at least 4 months. The persistence of responding at a reasonably high ratio and the exhibition of powerful stimulus control was attributed to the degree of training prior to the introduction of free food (see also McLaughlin, Kleinman, \& Vaughn, 1973). A further finding, that animals respond even when not food deprived, was recently confirmed by Bilbrey, Patterson, \& Winokur (1973) in pigeons and partially confirmed by Tarte and Snyder (1972) in rats.

The demonstration of decreased responding during extinction and following continuous access to food, in the previous study (Davidson, 1971), suggested that responding was directly related to response contingent food reinforcement. Jensen (1963) attributed responding for food in the presence of free food to an "intrinsic appeal" of response contingent reinforcement; Neuringer (1969), to the motivational properties of the activity which produces food; and Wallace, Osborne, Norborg, and Fantino (1973), to the reinforcing properties of the stimulus change that accompanies and includes response produced food delivery. All three of

Elkan Gamzu sponsors and takes full editorial responsibility for this paper. The present address of A. B. Davidson is Pharmacology Department, Hoffman-La Roche, Inc. Nutley, New Jersey 07110. these alternatives imply that this behavior is largely independent of any motivational appetitive properties of the food reinforcements. This report presents evidence, based on pharmacological results, that the appetitive properties of food reinforcements play a major role in the maintenance of this behavior.

Glow and Russell (1973) reported that d-amphetamine markedly enhanced responding when sensory stimulus change was used as the sole reinforcer. d-Amphetamine should therefore produce a marked increase in the presence of free food. Similarly, d-amphetamine should also increase responding if food producing activity itself has motivational properties, since d-amphetamine increases motor activity. If, however, the appetitive properties of response contingent food play an important role in the maintenance of responding, then the administration of d-amphetamine, a potent anorectic agent, should decrease responding. This report describes the effects of d-amphetamine and fenfluramine, an anorectic which does not produce amphetamine-like motor stimulant effects, on responding for food in the presence of free food.

\section{METHOD}

These experiments were conducted on three of the rats (male Charles River) used in the previously reported series of experiments (Davidson, 1971). Initially, they had been reduced to approximately $80 \%$ of their ad-lib weights (mean $=180 \mathrm{~g}$ ) by food deprivation. They were automatically trained to press a key on a multiple schedule of reinforcement in a $23 \times 23 \times 20 \mathrm{~cm}$ operant conditioning chamber (Davidson, Davis, \& Cook, 197l). When the chamber was lit, responses on the key were reinforced by the delivery of a $45-\mathrm{mg}$ Noyes food pellet at a fixed ratio of 10 responses per reinforcement (FR 10). Following the delivery of each reinforcement, the chamber was darkened and a 1-min timeout period ensued, during which responses on the key were ineffective in producing food. These two conditions alternated regularly, in each daily session, for a total of 60 reinforcements. After 56 daily sessions (weekends excepted), during which the 
Table 1

\begin{tabular}{|c|c|c|c|c|}
\hline \multirow[b]{2}{*}{ Compound } & \multirow[b]{2}{*}{ 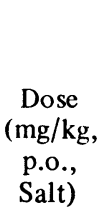 } & \multicolumn{3}{|c|}{$\begin{array}{c}\text { Mean Percentage Change } \\
\text { from Control }\end{array}$} \\
\hline & & $\begin{array}{c}\text { Keypress } \\
\text { Response } \\
\text { Rate }\end{array}$ & $\begin{array}{l}\text { Response- } \\
\text { Produced } \\
\text { Food Con- } \\
\text { sumption }\end{array}$ & $\begin{array}{c}\text { Free } \\
\text { Food Con- } \\
\text { sumption }\end{array}$ \\
\hline $\begin{array}{l}\text { d-Amphetamine- } \\
\mathrm{SO}_{4}\end{array}$ & $\begin{array}{l}.5 \\
1 \\
2 \\
4\end{array}$ & $\begin{array}{c}-34 \\
-46 \\
-94 * \\
-100^{*}\end{array}$ & $\begin{array}{c}-17 \\
-70^{*} \\
-89 * \\
-100^{*}\end{array}$ & $\begin{array}{c}-17 \\
+5 \\
-31 \\
-100^{*}\end{array}$ \\
\hline Fenfluramine-HCl & $\begin{array}{l}2 \\
4 \\
8\end{array}$ & $\begin{array}{l}-81^{*} \\
-90^{*} \\
-82^{*}\end{array}$ & $\begin{array}{l}-79^{*} \\
-89^{*} \\
-86^{*}\end{array}$ & $\begin{array}{l}-38^{*} \\
-40 \\
-53^{*}\end{array}$ \\
\hline
\end{tabular}

${ }^{*} p<.05$, matched pairs $t$ test, two-tailed

rats were maintained at reduced body weight by limited feeding, a contact-sensitive foodcup $(8.2 \mathrm{~cm}$ diam $\times 4.1 \mathrm{~cm}$ deep) was placed in the experimental chamber. The cup contained a measured amount ( $35 \mathrm{~g}$ ) of the same pellets used to reinforce keypressing and was fixed to the floor in the corner of the chamber furthest from the key and reinforcement tray. No attempt was made to restrict the amount of food the rats could consume during an experimental session or to control their body weights from this time to the conclusion of the study. The rats were at liberty to eat free food from the foodcup or to work for food by pressing the key on the FR 10 schedule of reinforcement. The experiments reported earlier (Davidson, 1971) were completed over a period of 137 calendar days, at which time performance was restored to stable control levels, and the present experiments were begun. In these experiments, the rats were maintained on a $23-\mathrm{h}$ food-deprivation schedule between sessions.

The rats' performance on the day of drug treatment was compared to their mean performance levels on the 3 preceding days. Aqueous solutions of d-amphetamine-SO or fenfluramine- $\mathrm{HCl}$ were administered orally, by gavage, $30 \mathrm{~min}$ before the sessions were begun. d-Amphetamine was administered at doses of $.5,1,2$, or $4 \mathrm{mg} / \mathrm{kg}$ and fenfluramine at doses of 2,4 , or $8 \mathrm{mg} / \mathrm{kg}$ (doses were calculated as the salt form). All rats received all treatments, and 1 week elapsed between treatments. The amount of free food consumed by each rat was determined by weighing the amount of food remaining in the cup at the end of each session; the amount of response produced food consumed was calculated from the number of reinforcements delivered. All rats consumed all response produced food pellets and only a negligible number of food pellets were occasionally dropped from the free foodcup.

\section{RESULTS}

Table 1 shows the mean percent change from control for each of the three parameters studied. Within the range of doses studied, d-amphetamine produced dose-related statistically significant decreases in keypress response rate and in both response produced and free food consumption. These measures were also significantly decreased by fenfluramine, though not in a dose related manner. With both compounds, keypressing and response produced food consumption, a related measure, appeared to be affected to a greater extent than was free food consumption.

\section{DISCUSSION}

Both d-amphetamine and fenfluramine are potent anorectic compounds. In addition, d-amphetamine is a locomotor stimulant and is particularly effective in increasing low rates of responding, even when the responding is maintained by food reinforcement (see reivew by Cole, 1970). Fenlfuramine depresses locomoto: activity (le Douarec and Neveu, 1970). If responding in the presence of free food was independent of the delivery of food reinforcements, one would expect d-amphetamine to produce an increase in keypressing, either as a result of motor stimulant activity or of its effect on low rates of responding and a concomitant decrease in free food consumption due to anorexia. Fenfluramine would be expected to decrease both keypressing and food consumption. If the maintenance of responding in the presence of free food were primarily dependent on stimulus change (Wallace et al., 1973), one would similarly expect d-amphetamine to increase responding (Glow and Russell, 1973).

If, however, the appetitive motivational properties of the food reinforcement itself were major factors in the maintenance of responding for food in the presence of free food, one would expect the results which were obtained in these experiments. The anorectic activity of both compounds significantly reduced the already low rate of food producing behavior. Because of the availability of free food, the food obtained by keypressing was a weak reinforcer and consequently keypressing was a relatively weak behavicr. This was evidenced previously (Davidson, 1971) by a decrease in response rate from 160 responses per minute in the absence of free food to approximately 14 per minute after the introduction of free food. It was also evidenced in these experiments by the apparently greater sensitivity of keypressing and response produced food consumption to the effects of these anorectic compounds, relative to their effect on free food consumption.

The results reported here further support the proposition that, even in the presence of free food, responding for food reinforcement is substantially maintained by the reinforcing properties of the food itself, though effects due to stimulus change cannot be completely excluded. The strong stimulus control exhibited by the rats emphasizes the relationship of this behavior to the effects of their early training history.

\section{REFERENCES}

Bilbrey, J. L., Patterson, D. D., \& Winokur, S. Maintenance and autoshaping of keypecking in undeprived pigeons. Bulletin of the Psy chonomic Society, 1973, 2, 394-396.

Carder, B., \& Berkowitz, K. Rats; Preference for earned in comparison with free food. Science, 1970, 167, 1273-1274.

Cole, S. D. Experimental effects of amphetamine: Supplementary report. Perceptual and Motor Skills, 1970, 31, 223-232.

Davidson, A. B. Factors affecting key press responding by rats in the presence of free food. Psychonomic Science, 1971, 24, 135-137.

Davidson, A. B., Davis, D. J., \& Cook, L. A rapid automatic technique for generating operant key-press behavior in rats. Journal of the Experimental Analysis of Behavior, 1971, 15, 123-127.

Glow, P. H., \& Russell, A. Effects of dexamphetamine, amylobarbitone sodium and their mixture on sensory contingent bar pressing behavior in the rat. Psychopharmacologia (Berl.), 1973, 239-251.

Jensen, G. D. Preference for bar pressing over "freeloading" as a function of number of rewarded presses. Joumal of Experimental Psy chology, 1963, 65, 451-454.

LeDouarec, J. C., \& Neveu, C. Pharmacology and biochemistry of fenfluramine. In E. Costa and S. Garattini (Eds.), International Symposium on Amphetamines and Related Compounds. New York: Raven Press, 1970. Pp. 75-105.

McLaughlin, R. J., Kleinman, K. M., \& Vaughn, L. G. Effects of prior training at lever pressing on rats' subsequent responding for food or water in the presence of free rewards. Proceedings, 81 st Annual Convention, American Psychological Association, $1973,845-846$. 
Neuringer, A. J. Animals respond for food in the presence of free food. Science, 1969, 166, 399-401.

Neuringer, A. J. Many responses per food reward with free food present. Science, 1970, 169, 503-504.

Singh, D. Preference for bar pressing to obtain reward over freeloading in rats and children. Journal of Comparative and Phy siological Psy chology, 1970, 73, 320-327.

Tarte, R. D., \& Snyder, R. L. Barpressing in the presence of free food as a function of food deprivation. Psychonomic Science, $1972,26,169-170$.
Wallace, R. F., Osborne, S., Norborg, J., \& Fantino, E. Stimulus change contemporaneous with food presentation maintains responding in the presence of free food. Science, 1973, 182, 1038-1039.

(Received for publication March 3, 1975.) 